\title{
Socioeconomic Drivers of Environmental Pollution in China: A Spatial Econometric Analysis
}

\author{
Jianmin Liu, ${ }^{1,2}$ Xia Chen, ${ }^{1}$ and Runchu Wei ${ }^{3}$ \\ ${ }^{1}$ School of Economics \& Trade, Hunan University, Changsha, Hunan Province 410079, China \\ ${ }^{2}$ Hunan University of Finance and Economics, Changsha, Hunan Province 410025, China \\ ${ }^{3}$ School of Hydraulic Engineering, Changsha University of Science and Technology, Changsha, Hunan Province 410114, China \\ Correspondence should be addressed to Runchu Wei; weirunchu@163.com
}

Received 20 April 2017; Accepted 11 June 2017; Published 3 August 2017

Academic Editor: Ricardo López-Ruiz

Copyright (C) 2017 Jianmin Liu et al. This is an open access article distributed under the Creative Commons Attribution License, which permits unrestricted use, distribution, and reproduction in any medium, provided the original work is properly cited.

\begin{abstract}
This paper studies the environmental pollution and its impacts in China using prefecture-level cities and municipalities data. Moran's $I$, the widely used spatial autocorrelation index, provides a fairly strong pattern of spatial clustering of environmental pollution and suggests a fairly high stability of the positive spatial correlation. To investigate the driving forces of environmental pollution and explore the relationship between fiscal decentralization, economic growth, and environmental pollution, spatial Durbin model is used for this analysis. The result shows that fiscal decentralization of local unit plays a significant role in promoting the environmental pollution and the feedback effect of fiscal decentralization on environmental pollution is also positive, though it is not significant. The relationship of GDP per capita and environmental pollution shows inverted U-shaped curve. Due to the scale effect of secondary industry, the higher the level of secondary industry development in a unit is, the easier it is to attract the secondary industry in adjacent units, which mitigates the environmental pollution in adjacent units. Densely populated areas tend to deteriorate local environment, but environmental regulation in densely populated areas is often tighter than other areas, which reduces environmental pollution to a certain extent.
\end{abstract}

\section{Introduction}

Since the adoption of reform and opening up policies in 1978, China's rapid economic growth has been well documented and widely touted with an average annual growth rate of 9.8\% in gross domestic product (GDP) from 1979 to 2013 (http://www.southcn.com/nfdaily/news/content/2013-11/06/ content_83873781.htm). Besides, China has replaced Japan as the second largest economy by 2010 [1]. In the meanwhile, China's industrialization process also has accelerated and over half of its population now lives in urban areas [2]. Along with the impressive economic and social performance, natural resources are consumed more and more quickly and massive pollutants are released; thus, the environmental qualities have become worse and worse, which affect human life and threaten the survival of mankind seriously [3]. In 2006,13 of the world's 20 most polluted cities are in China [4]. Besides, China has become the largest carbon emitter among the world in 2007 [5]. Less than $1 \%$ of the 500 largest cities in China meet the air quality standards recommended by the World Health Organization and 7 cities are ranked among the 10 most polluted cities in the world [6]. Thus, environmental pollution has been a major concern in recent years. Researches from different angles have been launched by scholars from both domestic and abroad, such as finance $[7,8]$ as well as economic development $[9,10]$ and foreign investment $[11,12]$.

\section{Literature Review}

Many theoretical and empirical studies have examined the relationship between fiscal decentralization and environmental pollution. The debate continues whether fiscal decentralization will improve or deteriorate environmental quality [1316]. Environmental federalism held the opinion that the local governments would pursue economic development at the price of heavy pollution emissions when the spillover effect 
was taken into account; that is, the impact of fiscal decentralization on the quality of environment was negative [17]. The traditional environmental federalism held the similar point that environment pollution had significant externality and it would lead to the phenomenon of environment regulatory "race to the bottom," lowering the standards of environmental regulator [18]. Sigman [19-21] analyzed the spillover effect of interstate river pollution and came to the conclusion that the government management was ineffective for the existence of spillover effects. Besides, the evidence that water pollution accelerated along with degree of fiscal decentralization increases was proved.

After the tax sharing reform in 1994, taxes were reassigned between the central and local governments; thus, the intergovernmental relationship in China showed such a framework with Chinese characteristics that local governments have greater financial autonomy and central government has the political decision-making power. Both political and economic incentives became the core of China's governances $[22,23]$. Under the incentives and constraints of the central government, local governments had greater autonomy in local affairs, which made a significant impact on environmental planning and protection [7]. Local governments only cared about the economic development, and they even sacrificed environment in return for rapid economic growth [24]. Many scholars drew a conclusion that Chinese-style fiscal decentralization exacerbated environmental pollution through empirical research. Ruilong et al. [25] formulated a dynamic panel data model to test the impact of China's fiscal decentralization on environmental quality; the results showed that the degree of fiscal decentralization has a significant negative impact on the quality of environment. Meng [26] estimated the feedback mechanism of environmental pollution and fiscal revenue per capita by using simultaneous equations; he found that there exists significantly inverted U-curve relationship between the degree of environmental pollution and local fiscal capacity per capita. Wen-Juan and Mao-Chu [27] analyzed the relationship between industrial emissions and fiscal decentralization by panel data model; the result shows that Chinese-style fiscal decentralization increases the emissions intensity of spillover public goods such as wastewater and waste gas. Jinru [28] analyzed the relationship between fiscal decentralization and energy consumption per unit of GDP using provincial panel data and discovered that fiscal decentralization led to the phenomenon of "race to the bottom," which reduces the local governments' incentives of energy conservation. Fang et al. [29] held the opinion that China's environmental problems are mainly due to the extensive mode of economic development, and the root of this extensive development model is government action under Chinese-style fiscal decentralization. The developments of most provinces were far away from Kuznets turning point now, so waiting for the arrival of Kuznets turning point passively was not a good choice and environmental governance mainly relied on internal dynamism of economic growth mode transformation as well as policy incentives.

The relationship of economic growth and environmental degradation also had been widely concerned [30-33]. The debate focused on whether environmental quality will improve or deteriorate as economic developing. According to the environmental Kuznets curve (EKC) theory, the environmental pollution level increased with income firstly but decreased after economic development reached certain turning point eventually; that is, there exists inverted U-shaped relationship between economic growth and environmental pollution [34-36]. Many empirical studies had been conducted to test the relationship between economic growth and environmental pollution, and mixed findings were reported. One point of view was that environmental pollution increased with economic growth due to the increasing need for energy and materials $[37,38]$. Besides, there also exist the view that the results depended on the type of pollutants and specific econometric models $[39,40]$.

Most studies in current literatures are based on provincial level data and few of the analysis are from the view point of spatial effects. This paper contributes to the literature in the following ways. Firstly, this paper represents the first study that uses detailed prefecture-level city data to investigate the relationship between fiscal decentralization and environmental pollution in China. As pollution sources are diverse, environmental pollution shows significantly territorial features. The governments of prefecture-level cities and municipalities play an important role in environmental pollution treatment, so analyses limited to provincial level are likely to ignore the discrepancies that exist among provinces [41]. Secondly, environmental pollution is not caused by a single pollutant; it is the result of combined effects by various pollutants. Comprehensive evaluation on environmental pollution may improve the explanatory power of empirical models [42]. Thus, environmental pollution is measured by the environmental pollution index in this paper, which is used as dependent variable that helps to reflect the level of environmental pollution. Thirdly, spatial econometric models are employed to reveal the relationship between fiscal decentralization and environmental pollution; besides, other socioeconomic variables including economic growth, foreign direct investment, industrial structure, and population density are incorporated as independent variables that help explain the spatial patterns of environmental pollution.

The paper is organized as follows. Section 3 describes the status of environmental pollution and analysis of regional spatial correlation in Chinese prefecture-level cities. Section 4 shows the spatial effect models. Section 5 lists the empirical results. Section 6 contains conclusions and suggestions.

\section{The Status of Environmental Pollution and Regional Spatial Correlation}

3.1. Calculation Steps of Environmental Pollution Index. Evaluation of environmental pollution should be based on the objective facts and avoid interference caused by human subjective factors. Therefore, the method of dynamic comprehensive evaluation is used to analyze the regional environmental pollution index.

Yang [43] proposed the specific steps of dynamic comprehensive evaluation method, which is as follows. 
Firstly, normalize the data. As different indictors have different dimensions and units, nondimensional treatment is a must to eliminate the incommensurability brought by different dimensions and units. Assuming $\left\{x_{i j}\left(t_{k}\right)\right\}$ is the value of sample $i$ 's $j$-th index at time $t_{k}(i=1,2, \ldots, m, j=$ $1,2, \ldots, n, k=1,2, \ldots, T)$, the method of data normalization is given by

$$
x_{i j}^{\prime}\left(t_{k}\right)=\frac{x_{i j}\left(t_{k}\right)-\overline{x_{i j}\left(t_{k}\right)}}{s_{j}\left(t_{k}\right)},
$$

where $x_{i j}^{\prime}\left(t_{k}\right)$ is the data after being normalized, $i$ represents prefecture-level city, $j$ represents pollution index, $x_{i j}\left(t_{k}\right)$ represents the original value of pollutants, and $\overline{x_{i j}\left(t_{k}\right)}$ and $s_{j}\left(t_{k}\right)$ denote the mean value and standard deviation of $j$-th index at time $t_{k}$, respectively.

Secondly, calculate the weight $w_{j}$. Before we calculate the weight of pollutant indexes, real symmetric matrix $H_{k}=$ $X_{k}^{t} X_{k}(k=1,2, \ldots, T)$ should be calculated, in which

$$
X_{k}=\left|\begin{array}{ccc}
x_{11}^{\prime}\left(t_{k}\right) & \cdots & x_{1 m}^{\prime}\left(t_{k}\right) \\
\cdots & \cdots & \cdots \\
x_{n 1}^{\prime}\left(t_{k}\right) & \cdots & x_{n m}^{\prime}\left(t_{k}\right)
\end{array}\right| .
$$

Besides, it is a must to solve the matrix eigenvalues and the standard feature vectors $\lambda$ corresponding to the matrix eigenvalues of the real symmetric matrix $H$, in which $H=$ $H_{1}+H_{2}+\cdots+H_{k}(k=1,2, \ldots, T)$. Then we will normalize standard feature vectors $\lambda$ and the value of $\lambda_{j}$ is the combined weight $w_{j}$.

Thirdly, calculate the environmental pollution index $P_{i}\left(t_{k}\right)$. The method of calculating the environmental pollution index is given by

$$
\begin{aligned}
P_{i}\left(t_{k}\right)=\sum_{j=1}^{n} w_{j} x_{i j}^{\prime}\left(t_{k}\right), & \\
& (i=1,2, \ldots, m, k=1,2, \ldots, T),
\end{aligned}
$$

where $P_{i}\left(t_{k}\right)$ represents the environmental pollution index of region $i$ at time $t_{k}$ and $w_{j}$ represents the weight values of pollutant $j$.

3.2. Status of Environmental Pollution. This study concerns a selection of prefecture-level cities and municipalities in China. In view of the serious loss of data in some cities, panel data of 272 cities from 2003 to 2012 are selected and the study area is shown in Figure 1. The data are mainly from China City Statistical Yearbook and China Statistical Yearbook of 2004 to 2013. The environmental pollution index contains industrial wastewater emissions per capita (tons/person) and industrial emissions per capita, that is, sulfur dioxide emissions per capita (tons/million) and smoke (powder) dust emissions per capita (tons/million). Per capita emission levels can exclude the impact of population size in each region, which could reflect the environmental quality of local residents better.

The weight values corresponding to the maximum eigenvalue determined by real symmetric matrix are $w_{1}=0.1868$,

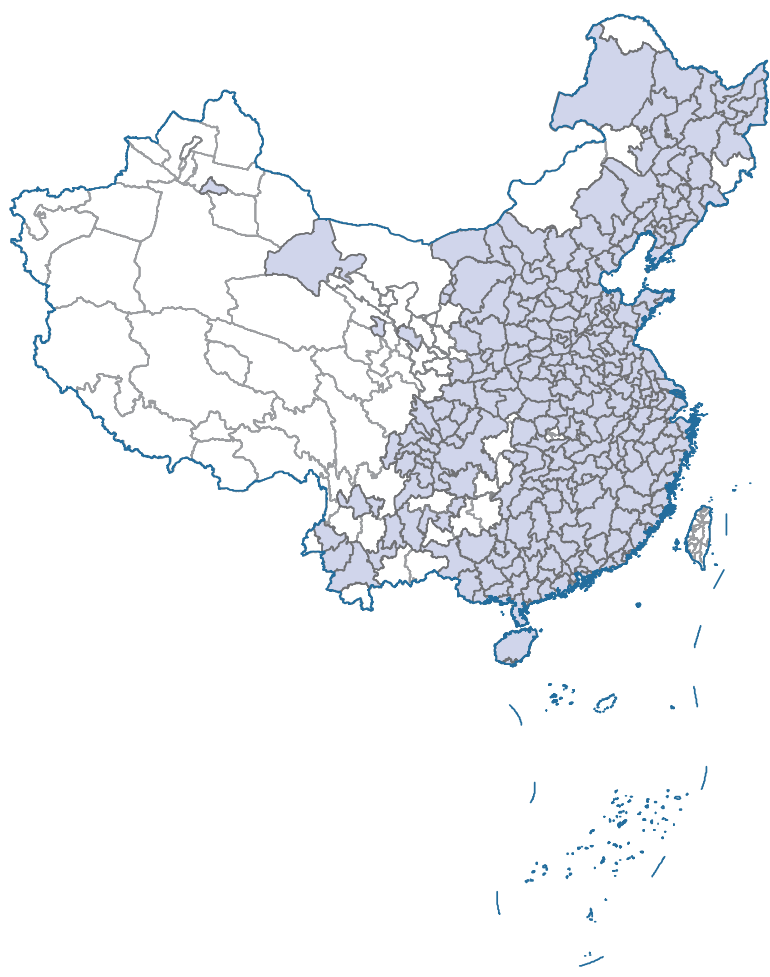

Studying areas

Nonstudying areas

Figure 1: The study area.

$w_{2}=0.4177$, and $w_{3}=0.3955 . w_{1}, w_{2}$, and $w_{3}$ represent the weight values of industrial wastewater emissions per capita, sulfur dioxide emissions per capita, and smoke (powder) dust emissions per capita, respectively. Given the space limitations, the environmental pollution indexes of ten representative cities are listed in Table 1 (the environmental pollution indexes of all cities are present by request).

3.3. Spatial Correlation Analysis of Environmental Pollution. In order to test whether there exist spatial effects, global spatial autocorrelation test and local spatial autocorrelation test are used to reveal the spatial properties. There are two forms of Moran's $I$. The global Moran's $I$ is a measure to describe the overall spatial relationship across all geographic units for the entire study area and reflects the average of the same variables for the entire study [44-46].

Local Moran's $I$ is a measure to describe the heterogeneity of spatial association across different geographic units for the study area and reflects the variation degree of the same variables in space $[45,47]$.

3.3.1. Global Spatial Correlation. The global Moran's $I$ is calculated from the following formula [9]:

$$
\text { Moran's } I=\frac{n \sum_{i=1}^{n} \sum_{j=1}^{n} w_{i j}\left(x_{i}-\bar{x}\right)\left(x_{j}-\bar{x}\right)}{\sum_{i}^{n} \sum_{j=1}^{n} w_{i j} \sum_{i=1}^{n}\left(x_{i}-\bar{x}\right)^{2}},
$$


TABLE 1: The environmental pollution index of ten cities.

\begin{tabular}{lcccccccccc}
\hline & 2003 & 2004 & 2005 & 2006 & 2007 & 2008 & 2009 & 2010 & 2011 & 2012 \\
\hline Beijing & -0.38 & -0.42 & -0.51 & -0.59 & -0.57 & -0.68 & -0.65 & -0.57 & -0.46 & -0.44 \\
Tianjin & 0.26 & 0.05 & 0.13 & 0.01 & 0.00 & -0.08 & -0.02 & 0.05 & -0.01 & 0.03 \\
Shijiazhuang & 0.23 & 0.15 & 0.02 & 0.07 & 0.05 & -0.29 & -0.26 & -0.21 & 0.01 & 0.10 \\
Tangshan & 1.44 & 0.90 & 0.80 & 0.86 & 0.87 & 1.25 & 0.88 & 0.66 & 0.84 & 0.76 \\
Qinhuangdao & -0.02 & -0.08 & -0.15 & -0.17 & -0.22 & -0.40 & -0.22 & -0.15 & 0.19 & 0.22 \\
Handan & 0.08 & 0.02 & -0.05 & -0.05 & -0.02 & -0.16 & -0.26 & -0.23 & 0.00 & -0.05 \\
Xingtai & -0.02 & -0.05 & -0.12 & -0.12 & -0.12 & 0.05 & -0.16 & -0.20 & -0.11 & -0.09 \\
Baoding & -0.46 & -0.47 & -0.50 & -0.52 & -0.56 & -0.68 & -0.64 & -0.52 & -0.36 & -0.33 \\
Zhangjiakou & 0.24 & 0.15 & 0.01 & 0.06 & 0.07 & -0.29 & -0.04 & 0.00 & -0.08 & -0.10 \\
Chengde & -0.24 & -0.12 & -0.15 & -0.13 & 0.08 & 0.13 & 0.16 & -0.02 & -0.07 & -0.10 \\
\hline
\end{tabular}

TABLE 2: Global Moran's I of environmental pollution index in 272 cities of China, 2003 to 2012.

\begin{tabular}{|c|c|c|c|c|c|}
\hline Years & Moran's I & $E(I)$ & $\operatorname{var}(I)$ & $Z$ & $P$ value \\
\hline 2003 & 0.3850 & -0.0037 & 0.0016 & 9.8158 & 0.0000 \\
\hline 2004 & 0.4228 & -0.0037 & 0.0015 & 10.9042 & 0.0000 \\
\hline 2005 & 0.4547 & -0.0037 & 0.0015 & 11.7872 & 0.0000 \\
\hline 2006 & 0.4503 & -0.0037 & 0.0016 & 11.4713 & 0.0000 \\
\hline 2007 & 0.4236 & -0.0037 & 0.0016 & 10.6792 & 0.0000 \\
\hline 2008 & 0.4156 & -0.0037 & 0.0017 & 10.2805 & 0.0000 \\
\hline 2009 & 0.4338 & -0.0037 & 0.0016 & 10.8598 & 0.0000 \\
\hline 2010 & 0.4804 & -0.0037 & 0.0015 & 12.3233 & 0.0000 \\
\hline 2011 & 0.3228 & -0.0037 & 0.0016 & 8.1697 & 0.0000 \\
\hline 2012 & 0.3415 & -0.0037 & 0.0015 & 8.9503 & 0.0000 \\
\hline
\end{tabular}

where $x_{i}$ and $x_{j}$ are values of pollutant $x$ in two geographic units (i.e., cities) $i$ and $j, \bar{x}=(1 / n) \sum_{i=1}^{n} x_{i}$ is the average of pollutant $x, n$ is the total number of geographic units (i.e., cities), $w_{i j}$ is the element of spatial weight matrix, and the spatial weight matrix formed by weight coefficients $w_{i j}$ is an integral part of spatial modeling. It is an $n \times n$ matrix with nonnegative elements describing the spatial arrangement of the cities in the sample. Let $w_{i j}=1$ if geographic units $i$ and $j$ are adjacent to each other; otherwise, $w_{i j}=0$, and the diagonal elements are set to zero by assumption, since no unit can be viewed as its own neighbor [48]. The computation of Moran's $I$ index is achieved by the software of MATLAB (2011a).

The statistical significance of Moran's $I$ can be tested using $Z$ statistics and the expected value of Moran's $I$, that is, $E(I)$ [45]. Standardized $Z$ statistics and $E(I)$ are, respectively, expressed as

$$
\begin{aligned}
Z & =\frac{I-E(I)}{\sqrt{\operatorname{var}(I)}}, \\
E(I) & =-\frac{1}{n-1}, \\
\operatorname{var}(I) & =\frac{n^{2} w_{1}+n w_{2}+3 w_{0}^{2}}{w_{0}^{2}\left(n^{2}-1\right)}-E^{2}(I),
\end{aligned}
$$

$$
\begin{aligned}
& w_{0}=\sum_{i=1}^{n} \sum_{j=1}^{n} w_{i j}, \\
& w_{1}=\frac{1}{2} \sum_{i=1}^{n} \sum_{j=1}^{n}\left(w_{i j}+w_{j i}\right)^{2}, \\
& w_{2}=\sum_{i=1}^{n}\left(w_{i}+w_{j}\right)^{2},
\end{aligned}
$$

where $w_{i}$ and $w_{j}$ are separately the sum of the elements of $i$-th and $j$-th row of spatial matrix. The values of global Moran's $I$ range from -1 to 1 .

The results of global Moran's $I$ are shown in Table 1. The statistical significance of the Moran's $I$ values are tested using both $Z$ test and $P$ values. The expected value of Moran's $I$ and variances are also included in Table 2.

As shown in Table 2 , the high $Z$ scores and low $P$ values suggest that Moran's $I$ values are highly significant statistically for the environmental pollution index (at 0.01 significant levels). Besides, the Moran's $I$ values are positive, indicating that environmental pollution in China has obvious positive spatial correlation; that is, for the areas whose environmental pollution index is high, there seems to be one or more adjacent areas whose environmental pollution index is high 
(i.e., high-high positive correlation); in the meanwhile, for the areas whose environmental pollution index is low, there seems to be at least one adjacent area whose environmental pollution index is low (i.e., low-low positive correlation).

To visually explore spatial correlation, Moran's I scatter plots which can illustrate the relationship between the values of the chosen attribute at a given location and the average value of the same attribute at neighboring locations are created. The four quadrants of the scatter plot correspond to four types of spatial correlation. The horizontal axis of the scatter plot represents the standardized environmental pollution index and the vertical axis represents the index space lags of standardized environmental pollution index. The oblique line indicates a linear trend of the scatters. Positive spatial correlation is shown in quadrant I and quadrant III; simultaneously, negative spatial correlation is shown in quadrant II and quadrant IV. Quadrant I indicates high values surrounded by high values $(\mathrm{HH})$; besides, quadrant II indicates low values surrounded by high values (LH), quadrant III indicates low values surrounded by low values (LL), and quadrant IV indicates high values surrounded by low values (HL) [49].

Figure 2 present Moran's I scatter plots in 2003, 2008, and 2012 (we have drawn Moran's I scatter plots from 2003 to 2012. Due to limited space, only three maps are listed). Most cities are found in quadrant I and quadrant III, suggesting a fairly high stability of the positive spatial correlation.

3.3.2. Local Spatial Correlation. Local Moran's $I$ is a local indicator of variations in space, which is often called local indicator of spatial association (LISA). Similar to global Moran's I, a high (positive) value of local Moran's I means the association of similar values, whereas a low (negative) value means the association of dissimilar values. The formula of local Moran's $I$ is given as follows [45]:

$$
\text { Local Moran's } I_{i}=\frac{n\left(x_{i}-\bar{x}\right) \sum_{j=1}^{n} w_{i j}\left(x_{j}-\bar{x}\right)}{\sum_{j=1}^{n} w_{i j}\left(x_{j}-\bar{x}\right)^{2}},
$$

where the operation of summing $j$ is limited to the surrounding areas $i$. Other symbols are the same meaning as that in global Moran's I (4).

To detect the local variation in spatial association, space lags are included. The maps drawn according to local Moran's $I$ are shown in Figure 3 (the map is calculated by MATLAB and drawn by ArcGIS. We have drawn the LISA maps from 2003 to 2012 but only listed three maps for the limited space).

\section{Model and Data}

\subsection{Spatial Econometric Models}

4.1.1. The Basic Formation of Spatial Models. When spatial effects exist, using OLS models to estimate the regression of the spatial data would lead to bias or invalid results [50]. Spatial regression models take spatial effects into consideration. The spatial lag model (SAR) and the spatial error model (SEM) are the basic spatial models, which are widely used in empirical research. The spatial Durbin model (SDM) that contains the spatial lag space of both explained variables and explanatory variables is applied not so widely as SAR and SEM models [51].

The expression for the spatial lag model is

$$
y_{i t}=\delta \sum_{j=1}^{N} w_{i j} y_{j t}+c+x_{i t} \beta+\varepsilon_{i t} \text {, }
$$

where $y_{i t}$ is the dependent variable of unit $i$ at time $t, \sum_{j} w_{i j} y_{j t}$ denotes the spatial interactions, $w_{i j}$ is the element of spatial weight matrix, and the definition of spatial weight matrix is the same as that in (4). $\delta$ is the spatial autoregressive coefficient and reflects the impact of spatial interaction in explained variable, whose value is limited to $\left(1 / r_{\min }, 1\right)$, in which $r_{\min }$ is the minimum nonnegative real roots of standardized spatial weights matrix. $x_{i t}$ is explanatory variable; $\beta$ is the coefficient for the $x_{i t}$ explanatory variable to be estimated. $\varepsilon_{i t}$ is residual obeying the classical assumptions. $c$ is constant parameter.

The expression for the spatial error model is

$$
y_{i t}=c+x_{i t} \beta+\varphi_{i t}, \quad \varphi_{i t}=\rho \sum_{j=1}^{N} w_{i j} \varphi_{j t}+\varepsilon_{i t},
$$

where $\rho$ is the spatial autoregressive coefficient, $\varphi_{i t}$ is the spatially autoregressive error term, and $\varepsilon_{i t}$ is the vector of independent disturbance term representing normal distribution. Other symbols are the same meaning as that spatial lag model (7).

The expression for the spatial Durbin model is

$$
y_{i t}=\delta \sum_{j=1}^{N} w_{i j} y_{j t}+x_{i t} \beta+\theta \sum_{j=1}^{N} w_{i j} x_{j t}+\varepsilon_{i t},
$$

where $\theta$ is similar to $\delta$. It is spatial autoregressive coefficient and reflects the impact of spatial interaction in explanatory variables. Other symbols are the same meaning as that spatial lag model (7) and spatial error model (8).

4.1.2. Fixed or Random Effects. The fixed effects model is generally more appropriate than the random effects model since spatial econometricians tend to work with space-time data of adjacent spatial units [52]. To test the assumption of zero correlation between the random effects $\mu_{i}$ and the explanatory variables, the Hausman specification test might be used [53]. The hypothesis being tested is $H_{0}: h=$ 0 , where $h=\mathbf{d}^{T}[\operatorname{var}(\mathbf{d})]^{-1} \mathbf{d}, \mathbf{d}=\widehat{\boldsymbol{\beta}}_{\mathrm{FE}}-\widehat{\boldsymbol{\beta}}_{\mathrm{RE}}, \operatorname{var}(\mathbf{d})=$ $\widehat{\sigma}_{\mathrm{RE}}^{2}\left(X^{\bullet T} X^{\bullet}\right)^{-1}-\widehat{\sigma}_{\mathrm{FE}}^{2}\left(X^{* T} X^{*}\right)^{-1}$. This test statistic has a Chi squared distribution with $K$ degrees of freedom. When extending to spatial models, the test statistic $d$ should be calculated by $\left[\widehat{\boldsymbol{\beta}}^{T}, \widehat{\delta}\right]_{\mathrm{FE}}^{T}-\left[\widehat{\boldsymbol{\beta}}^{T}, \widehat{\delta}\right]_{\mathrm{RE}}^{T}$ and has a Chi-squared distribution with $K+1$ degrees of freedom.

4.1.3. Direct and Indirect Effects. As interaction effect is an important part in spatial economic models, LeSage and Pace [48] examine the spillover effects based on cross-section 

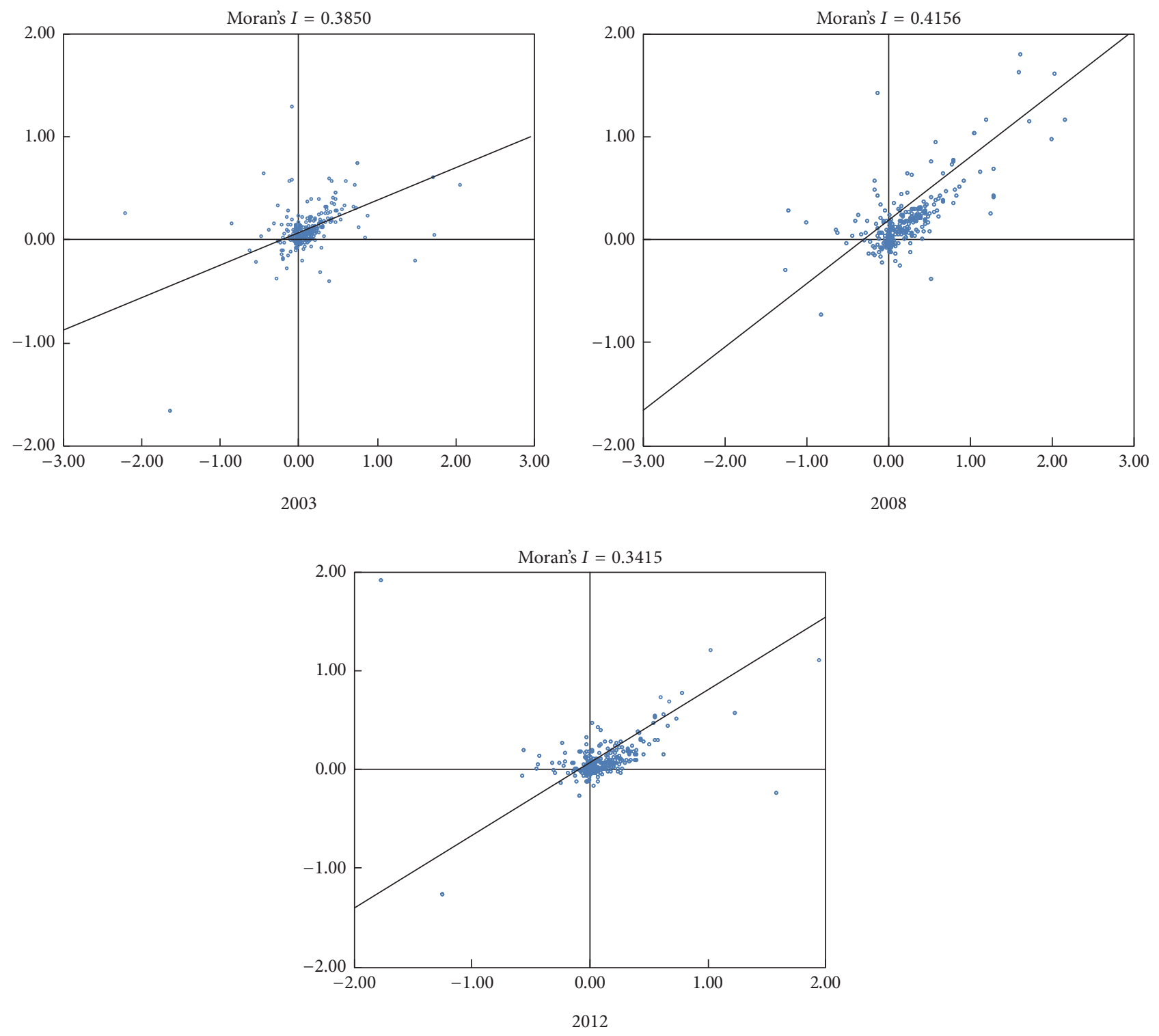

FIgURE 2: Moran's I scatter plot for environmental pollution index.

spatial model. Elhorst [54] extends the method to analyze spatial panel model and rewrites the method as $\mathbf{Y}=(\mathbf{I}-$ $\delta \mathbf{W})^{-1}(\mathbf{X} \boldsymbol{\beta}+\mathbf{W} \mathbf{X} \boldsymbol{\beta})+\mathbf{R}$, where $\mathbf{R}$ is a rest term containing the intercept and the error terms. The matrix of partial derivatives of the expected value of $\mathbf{Y}$ with respect to the $k$ th explanatory variable of $\mathbf{X}$ in unit 1 up to unit $\mathbf{N}$ in time can be seen to be

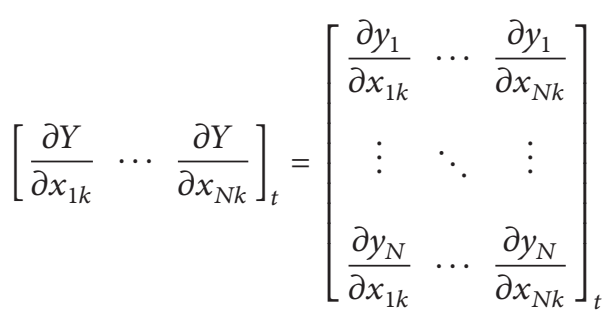

$$
=(\mathbf{I}-\delta \mathbf{W})^{-1}\left[\begin{array}{cccc}
\beta_{k} & W_{12} \theta_{k} & \cdots & W_{1 N} \theta_{k} \\
W_{21} \theta_{k} & \beta_{k} & \cdots & W_{2 N} \theta_{k} \\
\vdots & \vdots & \ddots & \vdots \\
W_{N 1} \theta_{k} & W_{N 2} \theta_{k} & \cdots & \beta_{k}
\end{array}\right]_{t}
$$

where $w_{i j}$ is the $(i, j)$ th element of $\mathbf{W}$. This result illustrates that the partial derivatives of $\mathbf{Y}$ with respect to the $k$ th explanatory variable have two important properties. If a particular explanatory variable in particular unit changes, not only will the dependent variable in that unit itself changes but also the dependent variables in other units will change; the first is called a direct effect and the second is called an indirect 


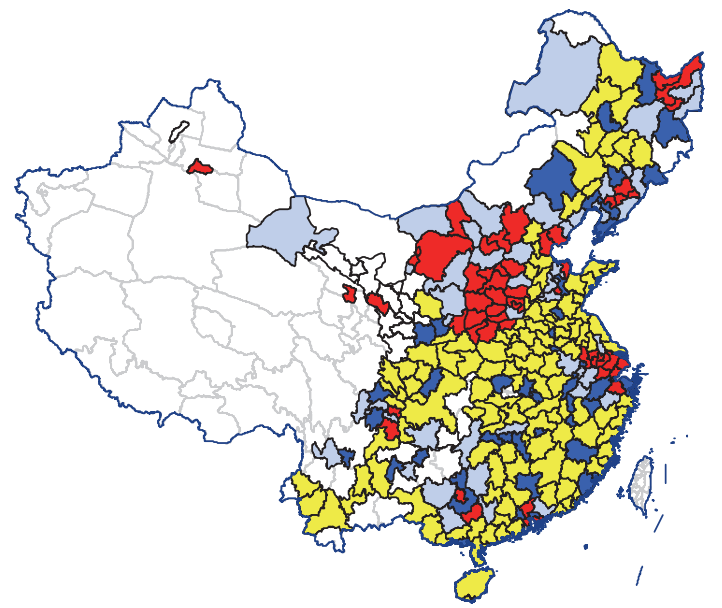

$1 \because 2.1$

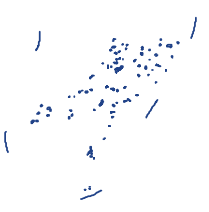

2003

Low-low

Low-high High-low
High-high

Nonstudying areas
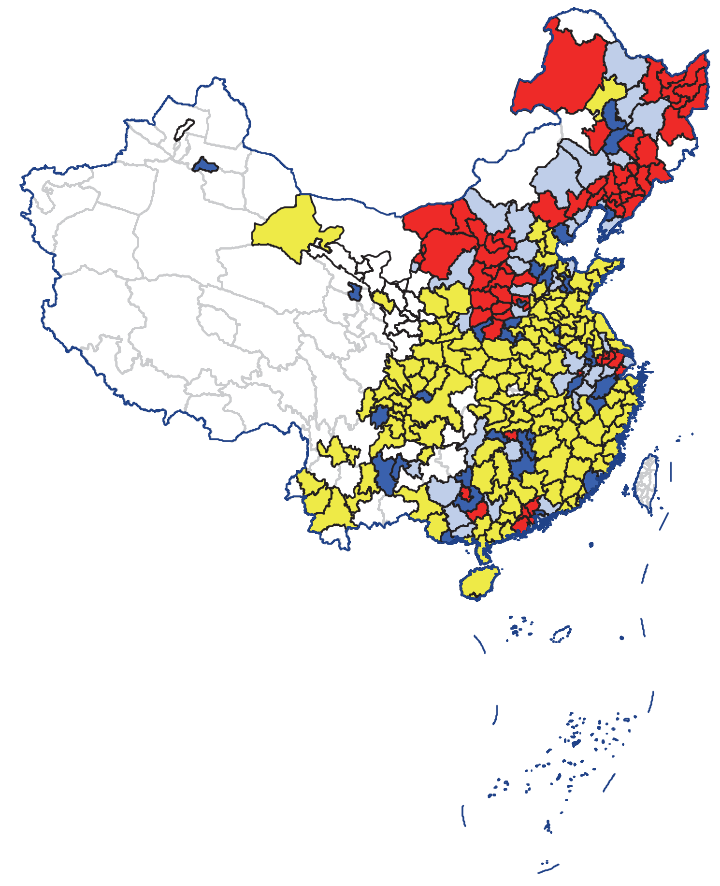

2008

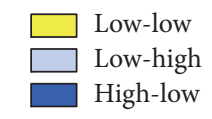

High-high

Nonstudying areas

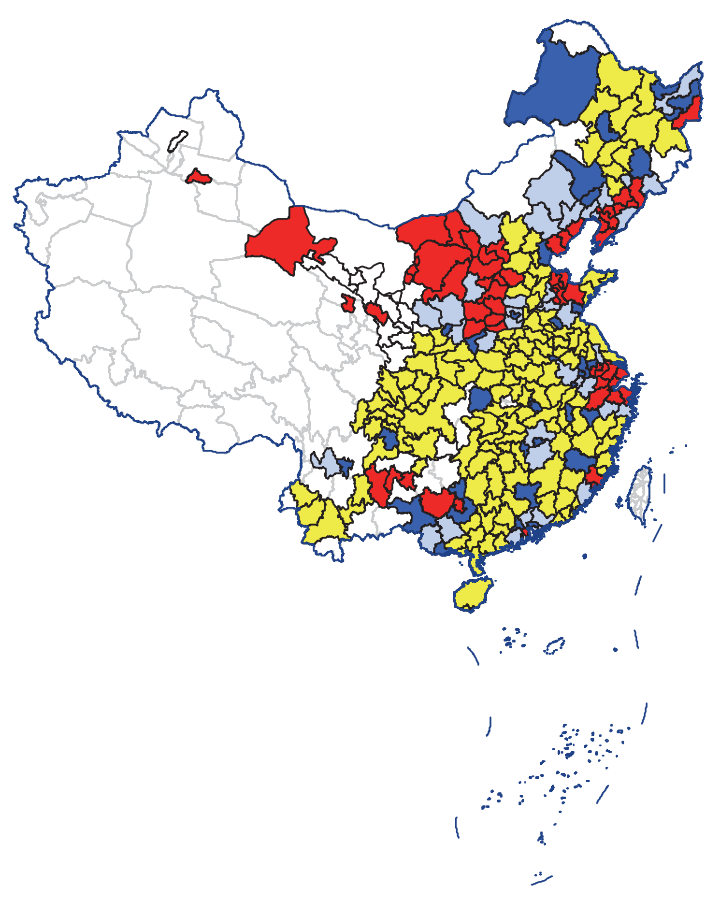

2012

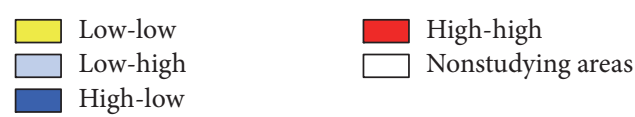

FIGURE 3: LISA maps of environmental pollution index. 
effect. The specific process of model selection and estimation refers to Elhorst $[51,54]$.

4.2. Data. The indicators selected are environmental pollution indicators, fiscal decentralization, foreign direct investment, economic growth, industrial structure, and population density. The data sources are the same as Section 3.2.

(1) Environmental Pollution (EPI). The environmental pollution index which contains industrial wastewater emissions per capita, industrial emissions per capita, and smoke (powder) dust emissions per capita is computed by dynamic comprehensive evaluation method as mentioned in Section 3.2.

(2) Fiscal Decentralization (FD). Fiscal decentralization is usually measured by average retention rate, the marginal retention rate, and the proportion of provincial expenditure per capita to the total financial expenditure per capita. Here fiscal decentralization is expressed as FD $=f d c /(f d c+$ $f d p+f d f)$ [55], where $f d c, f d p$, and $f d f$ denote the per capita expenditure of prefecture-level, provincial and central, respectively. This indicator can exclude the impact of population size and the transfers of central government to the local.

(3) Economic Growth (PGDP). GDP per capita is used to reflect the economic development of China (yuan). In order to test whether there is inverted U-shaped relationship between economic growth and environmental pollution, the square term of GDP per capita is also employed $[3,35,56]$.

(4) Foreign Direct Investment (FDI). FDI is usually measured by effective utilization of foreign capital. In order to reduce the impact of the normal economic growth on foreign direct investment, the proportion of foreign direct investment to local gross economic product is used to represent the case of local use of foreign capital.

(5) Industrial Structure (SEC). Energy was consumed largely and environment was polluted seriously during the process of industrialization; thus, proportion of secondary industry to local GDP is used to present industrial structure.

(6) Population Density (PD). Population density is calculated by total population dividing the local municipal land area $\left(\right.$ per $\mathrm{Km}^{2}$ ).

In order to eliminate the heteroscedasticity and collinearity, all the variables are logarithmic, and the descriptive statistics of indicators are shown in Table 3.

\section{Investigation of the Relationship between Fiscal Decentralization and Environmental Pollution: A Spatial Econometric Analysis}

5.1. Test of Spatial Effects. In order to test whether there exist spatial effects, nonspatial panel model is needed as a comparison. In the meanwhile, we need to determine whether the spatial lag model or the spatial error model is more appropriate [54]. When using the classic LM test or robust
LM test, if the hypothesis of no spatially autocorrelation is rejected, that is, there exists spatial dependence, then the suitable spatial panel model will be further determined by Wald test and likelihood ratio (LR) test.

According to Grossman and Krueger [35], the square term of GDP per capita can be used to reveal the relationship between economic development and environmental pollution more comprehensively. If the coefficient of square term is positive and the coefficient of simple term is negative, the relations between economic development and environmental pollution is $\mathrm{U}$-shaped curve, while if the coefficient of square term is negative and the coefficient of simple term is positive, the relations between economic development and environmental pollution are inverted $U$-shaped curve. Table 4 reports the estimation results when adopting a nonspatial panel data model and test results to determine whether the spatial lag model or the spatial error model is more appropriate.

Nonspatial panel parameter estimation and spatial autocorrelation test results are shown in Table 4. Table 4 shows us when the spatial panel data model should be used and which spatial panel data model is more appropriate.

As can be seen from Table 4, LM test and robust LM test results in pooled OLS model reject the null hypothesis of no spatially lagged dependent variable and the null hypothesis of no spatially autocorrelated error term at $1 \%$ significance level. LM test results in spatial fixed effects model and timeperiod fixed effects model reject the null hypothesis of no spatially lagged dependent variable and the null hypothesis of no spatially autocorrelated error term at $1 \%$ significance level; besides, robust LM test results in time-period fixed effect model reject the null hypothesis that there is no spatial lag term in explained variable and there are no spatial lag residuals at $1 \%$ and $5 \%$ significance level, respectively. If the model contains both time effects and spatial effects, when using the classic LM tests, the hypothesis of no spatially lagged dependent variable and no spatially autocorrelated error term can be rejected at $1 \%$ significance level, but when using the robust tests, the hypothesis of no spatially lagged dependent variable and no spatially autocorrelated error term cannot be rejected. The results above provide that spatial effects or spatial and time-period effects are included. Therefore, it is an important issue to determine whether spatial fixed effect model or spatial and time-period fixed effect model should be used. One of the criterions that may be used for this purpose is the likelihood ratio (LR) test based on the log-likelihood function values of the different models. The LR test is based on minus two times the difference between the value of the log-likelihood function in the restricted model (spatial fixed effects model or time-period fixed effects model) and the value of the log-likelihood function of the unrestricted model. The results are shown in Table 5.

The joint significance tests show that spatial fixed effects are significantly, while spatial and time-period fixed effects are not. Therefore, spatial fixed effects model should be built. The results in Table 3 show that both spatial lag effect and spatial error effect exist and further establishment of spatial Durbin model is a must. 
TABLE 3: Descriptive statistics of variables.

\begin{tabular}{lccccccc}
\hline Series & $N$ & $T$ & Obs & Mean & Std & Max & Min \\
\hline EPI & 272 & 10 & 2720 & 0 & 0.798 & 7.070 & -0.886 \\
FD & 272 & 10 & 2720 & 3.569 & 0.078 & 4.514 & 2.629 \\
PGDP & 272 & 10 & 2720 & 9.884 & 0.763 & 12.115 & 4.595 \\
FDI & 272 & 10 & 2720 & 2.819 & 1.648 & 6.118 & -2.303 \\
SEC & 272 & 10 & 2720 & 3.864 & 0.057 & 4.453 & 2.754 \\
PD & 272 & 10 & 2720 & 5.769 & 0.764 & 7.887 & 1.548 \\
\hline
\end{tabular}

TABLE 4: Estimation results of panel data models without spatial interaction effects.

\begin{tabular}{lcccc}
\hline & Pooled OLS & Spatial fixed effects & Time-period fixed effects & Spatial and time-period fixed effects \\
\hline FD & $0.6802^{* * *}(9.1618)$ & $0.3660^{* * *}(3.9193)$ & $0.4001^{* * *}(5.1477)$ & $0.1393^{* * *}(3.7663)$ \\
FDI & $-0.0314^{* *}(-2.5529)$ & $-0.0070(-0.7350)$ & $-0.0566^{* * *}(-4.5798)$ & $-0.0073(-0.7634)$ \\
SEC & $1.0419^{* * *}(15.5283)$ & $0.1027(1.2399)$ & $0.9357^{* * *}(14.0106)$ & $0.1116(1.3222)$ \\
PD & $-0.2038^{* * *}(-11.7753)$ & $-0.1088^{* *}(-2.2883)$ & $-0.2221^{* * *}(-13.0113)$ & $-0.1124^{* *}(-2.3561)$ \\
GDP & $-1.2683^{* * *}(-4.0918)$ & $0.5764^{* * *}(3.2666)$ & $-1.0800^{* * *}(-3.4731)$ & $0.6716^{* * *}(3.5725)$ \\
GDP & $0.0654^{* * *}(4.1316)$ & $-0.0326^{* * *}(-3.6446)$ & $0.0692^{* * *}(4.3632)$ & $-0.0401^{* * *}(-3.8442)$ \\
intercept & $0.9134(0.5919)$ & & & 0.4644 \\
$\sigma^{2}$ & 0.4831 & 0.1033 & 0.2723 & 0.1032 \\
$R^{2}$ & 0.2416 & 0.0144 & -2813.4 & -752 \\
log $L$ & -2867.7 & -768.6501 & $527.3881^{* * *}$ & $12.3951^{* * *}$ \\
LM spatial lag & $604.0905^{* * *}$ & $12.5084^{* * *}$ & $462.9329^{* * *}$ & $13.4994^{* * *}$ \\
LM spatial error & $558.9572^{* * *}$ & $13.7019^{* * *}$ & $69.1703^{* * *}$ & 1.5220 \\
robust LM spatial lag & $53.7319^{* * *}$ & 1.9313 & $4.7151^{* *}$ & 2.6264 \\
robust LM spatial error & $8.5987^{* * *}$ & $3.1248^{*}$ & \\
\hline
\end{tabular}

Notes: $T$-values are in parentheses. $*, * *, * * *$ denote statistical significance levels at $10 \%, 5 \%$ and $1 \%$, respectively.

TABLE 5: Joint significance test of spatial and time-period fixed effects.

\begin{tabular}{lccc}
\hline & LR & $N$ & Prob \\
\hline Spatial fixed effects & 4091.8760 & 272 & 0.0000 \\
Time-period fixed effects & 2.3934 & 10 & 0.9923 \\
\hline
\end{tabular}

5.2. Results of Spatial Durbin Model. Table 6 reports the estimation results of spatial Durbin model.

The first column in Table 6 gives the results when this model is estimated using the direct approach based on the original data centralization (demeaning) and the second column when the coefficients are bias corrected according to Elhorst [54]. The results in columns (1) and (2) show that the differences between the coefficient estimates of the direct approach and of the bias corrected approach are small for the independent variables and $\sigma^{2}$. By contrast, the coefficients of the spatially lagged dependent variable and of some independent variables appear to be relatively sensitive to the bias correction procedure. The third column shows the results of model random spatial effects bias corrected, which treat spatial effect as a random variable rather than a set of fixed effects. To determine whether fixed effects or random effects should be chosen, Hausman's specification test can be employed to test the random effects model against the fixed effects model based on the parameter estimations of spatial fixed effects model and asymptotic covariance matrix [57]. The results (10.1931, 13df, $P<0.01)$ indicate that the random effects model must be rejected and the spatial fixed model is more suitable.

To test the hypothesis whether the spatial Durbin model can be simplified to the spatial lag model, Wald or LR test may be performed. The values of Wald test and LR test are 10.3209 and 11.4602, respectively. Besides, both of statistics reject the null hypothesis at $10 \%$ or $5 \%$ significance level. Similarly, the hypothesis that the spatial Durbin model can be simplified to the spatial error model must be rejected for Wald test and LR test rejects the null hypothesis at $10 \%$ significance level. Therefore, the spatial Durbin model is chosen.

5.2.1. Spatial Interactions of Environmental Pollution. The results of spatial Durbin model with spatial fixed effects show that the environment pollution of one unit is not only influenced by the explanatory variables, such as fiscal decentralization, foreign direct investment, industrial structure, population density, and economic development, but also influenced by the environment pollution and explanatory variables of the adjacent units. The coefficient of spatially lagged dependent variable on the environment pollution is 0.0800 and significant at $1 \%$ significance level, which indicates that the cities adjacent to severe environmental pollution areas are more likely to be heavily environmentally polluted. 
TABLE 6: Estimation results of spatial Durbin model with spatial specific effects.

\begin{tabular}{|c|c|c|c|}
\hline & Spatial fixed effects & Spatial fixed effects bias corrected & Random spatial effects bias corrected \\
\hline$W * \mathrm{EPI}$ & $0.0810^{* * *}(2.9577)$ & $0.0800^{* * *}(2.9204)$ & $0.0800^{* * *}(2.9205)$ \\
\hline FD & $0.3292^{* * *}(3.2263)$ & $0.3292^{* * *}(3.2270)$ & $0.3292^{* * *}(3.4015)$ \\
\hline FDI & $-0.0001(-0.0042)$ & $-0.0001(-0.0050)$ & $-0.0001(-0.0053)$ \\
\hline SEC & $0.2374^{* *}(2.3791)$ & $0.2373^{* *}(2.3780)$ & $0.2373^{* *}(2.5066)$ \\
\hline $\mathrm{PD}$ & $-0.1251^{* *}(-2.3150)$ & $-0.1250^{* *}(-2.3146)$ & $-0.1250^{* *}(-2.4398)$ \\
\hline GDP & $0.6758^{* * *}(3.2926)$ & $0.6759^{* * *}(3.2927)$ & $0.6759^{* * *}(3.4708)$ \\
\hline $\mathrm{GDP}^{2}$ & $-0.0376^{* * *}(-3.3104)$ & $-0.0376^{* * *}(-3.3104)$ & $-0.0376^{* * *}(-3.4895)$ \\
\hline$W * \mathrm{FD}$ & $0.0857(0.5070)$ & $0.0862(0.5100)$ & $0.0862(0.5374)$ \\
\hline$W * \mathrm{FDI}$ & $-0.0195(-1.1330)$ & $-0.0195(-1.1332)$ & $-0.0195(-1.1945)$ \\
\hline$W * \mathrm{SEC}$ & $-0.2925^{* *}(-1.9925)$ & $-0.2926^{* *}(-1.9931)$ & $-0.2926^{* *}(-2.1009)$ \\
\hline$W * \mathrm{PD}$ & $0.0903(0.9492)$ & $0.0901(0.9475)$ & $0.0901(0.9988)$ \\
\hline$W * \mathrm{GDP}$ & $-0.3892(-1.1438)$ & $-0.3883(-1.1410)$ & $-0.3883(-1.2026)$ \\
\hline$W * \mathrm{GDP}^{2}$ & $0.0202(1.1467)$ & $0.0201(1.1437)$ & $0.0201(1.2054)$ \\
\hline$\sigma^{2}$ & 0.1134 & 0.1134 & 0.1021 \\
\hline$R^{2}$ & 0.8397 & 0.8397 & 0.0234 \\
\hline Corr $^{2}$ & 0.0181 & 0.0181 & 0.0181 \\
\hline $\log L$ & -765.2388 & -765.24067 & -31185.402 \\
\hline Wald test (SAR) & $11.4533^{*}$ & $10.3209^{*}$ & $11.4533^{*}$ \\
\hline LR test (SAR) & $11.4563^{*}$ & $11.4602^{* *}$ & NA \\
\hline Wald (SEM) & $10.4061^{*}$ & $9.3653^{*}$ & 10.4061 \\
\hline LR test (SEM) & $10.4034^{*}$ & $10.4075^{*}$ & NA \\
\hline
\end{tabular}

Notes: $T$-values are in parentheses. $*, * *$, and $* * *$ denote statistical significance levels at $10 \%, 5 \%$, and $1 \%$, respectively.

That is, the environmental pollution in China shows spatial aggregation features and the cities with serious pollution play significant role in promoting the environmental pollution adjacent to them.

5.2.2. Fiscal Decentralization and Environmental Pollution. The coefficient of fiscal decentralization affecting the environmental pollution in local unit is 0.3292 and significant at $1 \%$ significance level. The coefficient of fiscal decentralization in adjacent areas influenced by the environmental pollution in the local unit is positive, but it is not significant. This indicates that fiscal decentralization of local unit plays a significant role in promoting the environmental pollution. Besides, fiscal decentralization in adjacent areas will exacerbate the environmental pollution in local unit to some extent.

5.2.3. Economic Growth and Environmental Pollution. Firstly, we analyze the relationship between economic growth and environmental pollution from the perspective of the local space unit. The coefficients of GDP per capita and its squared term affecting the environmental pollution in local unit are 0.6759 and -0.0376 , respectively; those are both significant at $1 \%$ significance level, which confirms the inverted U-shaped relationship between GDP per capita and environmental pollution. Secondly, the relationship between economic growth and environmental pollution is taken from the perspective of the adjacent space units. The coefficients of GDP per capita and its squared term in adjacent areas are -0.3883 and 0.0201 , respectively, but they are not significant.
5.2.4. Foreign Direct Investment and Environmental Pollution. The coefficients of foreign direct investment and foreign direct investment in adjacent areas affecting the environmental pollution are -0.0001 and -0.0195 , respectively, but they are not significant at $10 \%$ significance level. This means that the effect of FDI on environmental pollution cannot be determined accurately through this model.

5.2.5. Industrial Structure and Environmental Pollution. The coefficient of industrial structure affecting the environmental pollution in local unit is 0.2373 and significant at $5 \%$ significance level. The coefficient of industrial structure in adjacent areas influenced by environmental pollution in local unit is -0.2926 and significant at $5 \%$ significance level. It indicates that the secondary industry of local unit plays a significant role in accelerating environmental pollution, while the secondary industry in adjacent areas slows down the environmental pollution in local unit. This may be due to the scale effect of secondary industry. The higher the level of secondary industry development in a unit is, the easier it is to attract the secondary industry in adjacent units, which mitigates the environmental pollution in adjacent units.

5.2.6. Population Density and Environmental Pollution. The regression coefficient of population density in local unit is -0.1250 and significant at 5\% significance level, meaning that the greater population density does not help aggravate environmental pollution. This may be due to the doubleedged sword of population density affecting the environmental pollution [58]; that is, densely populated areas tend 
TABLE 7: Direct and indirect effects of spatial Durbin model with spatial fixed effects.

\begin{tabular}{lccc}
\hline & Direct effect & Indirect effect & Total effect \\
\hline FD & $0.3271^{* * *}(3.2631)$ & $0.1211(0.6782)$ & $0.4483^{* *}(2.3426)$ \\
FDI & $-0.0001(-0.0060)$ & $-0.0208(-1.1465)$ & $-0.0208(-1.0786)$ \\
SEC & $0.2319^{* *}(2.3068)$ & $-0.2951^{*}(-1.8695)$ & $-0.0632(-0.4304)$ \\
PD & $-0.1255^{* *}(-2.3517)$ & $0.0873(0.8598)$ & $-0.0382(-0.3868)$ \\
GDP & $0.6734^{* * *}(3.2941)$ & $-0.3573(-1.0149)$ & $0.3161(0.8964)$ \\
GDP $^{2}$ & $-0.0374^{* * *}(-3.3410)$ & $0.0184(1.0121)$ & $-0.0190(-1.0835)$ \\
\hline
\end{tabular}

Notes: $T$-values are in parentheses. $*, * *$, and $* * *$ denote statistical significance levels at $10 \%, 5 \%$, and $1 \%$, respectively.

to deteriorate local environment; in the meanwhile, under this pressure, environmental regulation in densely populated areas is often tight than other areas, which reduces environmental pollution to a certain extent.

5.3. Direct and Indirect Effects. As spatial Durbin model is more suitable to describe the characteristics of space data, which means that it is biased when using nonspatial panel model, thus, comparing the differences between the two is put forward. However, Elhorst [54] pointed out that this comparison is invalid because the meanings of parameter estimations are not the same. Parameter estimates in the nonspatial panel model reflect the marginal impact of dependent variables when the explanatory variables change, while those include the interaction effects in the spatial Durbin model. Therefore, it is necessary to estimate the direct and indirect (spillover) effects. The direct effects, indirect effects, and total effects of explanatory variables are shown in Table 7.

The estimate coefficients and significance level of direct effects are nearly the same with those in spatial Durbin model, and the slight difference in values is due to the feedback effects. Spatial lag terms in dependent variables and explained variables are the cause of feedback effects.

The direct effect coefficient of fiscal decentralization affecting the environmental pollution is 0.3271 and significant at $1 \%$ significance level, while the coefficient of fiscal decentralization affecting the environmental pollution in nonspatial panel data model is 0.3660 and $11.89 \%$ overvalued. The coefficient of fiscal decentralization affecting the environmental pollution in spatial Durbin model is 0.3239; thus, the feedback effect of fiscal decentralization is 0.0032 , accounting for $0.98 \%$ of the direct effects. The direct effect coefficients of GDP per capita and its square term affecting the environmental pollution are 0.6734 and -0.037 ; both of them are significant at $1 \%$ significance level. While the coefficients in nonspatial panel data model are 0.5764 and -0.0326 , both of them are underestimated in nonspatial panel data model. The coefficients of GDP per capita and its square term affecting the environmental pollution in spatial Durbin model are 0.6759 and -0.0376 , respectively; both of them are significant at $1 \%$ significance level. The feedback effects of GDP per capita and its square term are negative. The direct effect coefficients of foreign direct investment, industrial structure, and population density affecting the environmental pollution are $-0.0001,0.2319$, and -0.1255 ; the latter two of them are significant at 5\% significance level, while the coefficients of the three affecting the environmental pollution in nonspatial panel data model are $-0.0070,0.1027$, and -0.1088 . The foreign direct investment and industrial structure are underestimated in nonspatial panel data model, while population density is overvalued. The coefficients of foreign direct investment, industrial structure, and population density affecting the environmental pollution in spatial Durbin model are $-0.0001,0.2373$, and -0.1250 , there exist negative feedback effects for the terms of industrial structure and population density, and the feedback effect of foreign direct investment is not obvious.

The direct effect of fiscal decentralization on environmental pollution is overestimated by a big margin in the nonspatial panel data model, while it is bias corrected in the spatial Durbin model. From the view of feedback effect, there are positive feedback effects of fiscal decentralization and the population density which influenced environmental pollution, while the effects of foreign direct investment and the industrial structure which influenced environmental pollution are negative. It is due to the independence of the fiscal decentralization and the competitiveness of foreign direct investment and industrial structure. The feedback effect of GDP per capita which influenced environmental pollution is negative, while the effect of its square term is positive. As both of them are not significant, it is not obvious that the economic development affects the environmental pollution of the adjacent areas through feedback effects. There exist spillover effects for parameter estimation in spatial Durbin model, while there are none in nonspatial panel data model. The spillover effects of explanatory variables play a role in the environmental pollution of different areas to some degree. The spillover effects of fiscal decentralization and population density are positive, while the spillover effects of foreign direct investment and industrial structure are negative. The total effect coefficient of fiscal decentralization on environmental pollution is 0.4483 and significant at 5\% significant level, indicating that fiscal decentralization has a significant role in promoting the environmental pollution.

\section{Conclusions}

In this paper, we put forward an empirical evaluation on the relationship between fiscal decentralization, economic growth, and environmental pollution by the method of spatial economic analysis. This study provides strong evidence of 
spatial autocorrelation of environmental pollution. The significant values of both global Moran'I and local Moran'I point to fairly strong pattern of spatial clustering of environmental pollution. This research has identified that most cities are in the types of $\mathrm{HH}$ and LL clusters, suggesting a fairly high stability of the positive spatial correlation.

The further analysis confirms that spatial Durbin model is more suitable for this study. The environment pollution of one unit is not only influenced by the explanatory variables but also influenced by the environment pollution and explanatory variables of the adjacent units. That is, there exists feedback effect of environmental pollution. Environment pollution shows significant spatial aggregation features; the cities with serious pollution play significant role in aggravating the environmental pollution adjacent to them. Fiscal decentralization of local unit plays a significant role in promoting the environmental pollution. The feedback effect of fiscal decentralization on environmental pollution is also positive, though it is not significant. There exists the inverted U-shaped relationship between GDP per capita and environmental pollution. In the meanwhile, the feedback effect of economic growth is not significant. When considering the effects of local space unit, the effects of industrial structure and population density affecting the environmental pollution are significant at 5\% significance level, while the foreign direct investment is not significant. When considering the effects of adjacent space areas, only the industrial structure is significant.

\section{Conflicts of Interest}

The authors declare that there are no conflicts of interest regarding the publication of this paper.

\section{Acknowledgments}

The authors are grateful to the support provided by the National Social Science Fund Project of China (no. 14BJY159).

\section{References}

[1] National Bureau of Statistics of China (NBSC), China Statistical Yearbook 2011, China Statistical Press, Beijing, China, 2011.

[2] B. $\mathrm{Xu}$ and B. Lin, "How industrialization and urbanization process impacts on $\mathrm{CO} 2$ emissions in China: evidence from nonparametric additive regression models," Energy Economics, vol. 48, pp. 188-202, 2015.

[3] W. Chen, "Economic growth and the environment," in Proceeding of the Annual Conference on Development and Change, Cape Town, 2007.

[4] World Bank, World Development Indicators 2006, World Bank Publications, 2006.

[5] International Energy Agency, Key World Energy Statistics, International Energy Agency, 2009.

[6] Q. Zhang and R. Crooks, Toward an environmentally sustainable future: Country environmental analysis of the People's Republic of China, 2012.
[7] K. Zhang, J. Wang, and X. cui, "Fiscal decentralization and environmental pollution: from the perspective of carbon emission," in China Industrial Economics, vol. 10, pp. 65-75, 2011.

[8] R. Lopez, G. I. Galinato, and A. Islam, "Fiscal spending and the environment: theory and empirics," Journal of Environmental Economics and Management, vol. 62, no. 2, pp. 180-198, 2011.

[9] Q. Li, J. Song, E. Wang, H. Hu, J. Zhang, and Y. Wang, "Economic growth and pollutant emissions in China: a spatial econometric analysis," Stochastic Environmental Research and Risk Assessment, vol. 28, no. 2, pp. 429-442, 2014.

[10] S. Peng and Q. Bao, "China's economic growth and environmental pollution: an empirical test based on generalized impulse response function," China Industrial Economy, vol. 5, pp. 15-23, 2006 (Chinese).

[11] J. Acharyya, "FDI, Growth and the Environment: Evidence from India on CO2 Emission during the last two decades," Journal of economic development, vol. 34, no. 1, p. 43, 2009.

[12] J. M. Dean, M. E. Lovely, and H. Wang, "Are foreign investors attracted to weak environmental regulations? Evaluating the evidence from China," Journal of Development Economics, vol. 90, no. 1, pp. 1-13, 2009.

[13] W. E. Oates, Fiscal federalism, Books, 1972.

[14] J. A. List and S. Gerking, "Regulatory federalism and environmental protection in the United States," Journal of Regional Science, vol. 40, no. 3, pp. 453-471, 2000.

[15] D. L. Millimet, "Assessing the empirical impact of environmental federalism," Journal of Regional Science, vol. 43, no. 4, pp. 711733, 2003.

[16] W. B. Cutter and J. R. DeShazo, "The environmental consequences of decentralizing the decision to decentralize," Journal of Environmental Economics and Management, vol. 53, no. 1, pp. 32-53, 2007.

[17] E. C. D. Silva and A. J. Caplan, "Transboundary pollution control in federal systems," Journal of Environmental Economics and Management, vol. 34, no. 2, pp. 173-186, 1997.

[18] M. Kunce and J. F. Shogren, "Efficient decentralized fiscal and environmental policy: a dual purpose Henry George tax," Ecological Economics, vol. 65, no. 3, pp. 569-573, 2008.

[19] H. Sigman, "International spillovers and water quality in rivers: do countries free ride?" National Bureau of Economic Research, 2001.

[20] H. Sigman, "Transboundary spillovers and decentralization of environmental policies," Journal of Environmental Economics and Management, vol. 50, no. 1, pp. 82-101, 2005.

[21] H. Sigman, "Decentralization and environmental quality: an international analysis of water pollution," National Bureau of Economic Research w13098, 2007.

[22] X. Xianxiang, W. Xianbin, and S. Yuan, "Local official and economic growth," Economic Research Journal, vol. 9, pp. 18-31, 2007 (Chinese).

[23] S. Kunrong and F. Wenlin, "Tax competition, region game and their efficiency of growth," Economic Research Journal, vol. 6, pp. 16-26, 2006 (Chinese).

[24] F. Yong and Z. Yan, "Chinese-style decentralization and fiscal expenditure structure bias: the cost for growth and competitive," Management World, vol. 3, pp. 4-12, 2007 (Chinese).

[25] Y. Ruilong, Q. Zhang, and Z. Yean, "Fiscal decentralization and environmental pollution: evidence from data on province level in China," in The Macro-Economic Report, School of Economics, Renmin University of China, 2007. 
[26] L. Meng, "Fiscal decentralization and environmental pollution: amendments to the Environmental Kuznets hypothesis," Economic Review, vol. 5, pp. 54-59, 2009 (Chinese).

[27] Y. Wen-Juan and Z. Mao-Chu, "Can Chinese-style fiscal decentralization increase environmental pollution," in Collected Essays on Finance and Economics, vol. 6, pp. 32-37, 2012.

[28] L. Jinru, "Fiscal decentralization, FDI and pollution haven hypothesis: based on study of provincial dynamic panel data," Statistics \& Information Forum, vol. 28, no. 11, pp. 60-65, 2013 (Chinese).

[29] C. Fang, D. Yang, and W. Mei-yan, "The political economy of emission in China: will a low carbon growth be incentive compatible in next decade and beyond?" in Economic Research Journal, vol. 6, pp. 4-12, 2008.

[30] A. John and R. Pecchenino, "An overlapping generations model of growth and the environment," Economic Journal, vol. 104, no. 427, pp. 1393-1410, 1994.

[31] S. Dasgupta, B. Laplante, H. Wang, and D. Wheeler, "Confronting the environmental Kuznets curve," Journal of Economic Perspectives, vol. 16, no. 1, pp. 147-168, 2002.

[32] W. Beckerman, "Economic growth and the environment: whose growth? whose environment?" World Development, vol. 20, no. 4, pp. 481-496, 1992.

[33] B. Copeland and M. S. Taylor, "Trade, Tragedy, and the Commons," National Bureau of Economic Research w10836, 2004.

[34] G. Grossman and A. Krueger, "Environmental Impacts of a North American Free Trade Agreement," National Bureau of Economic Research w3914, 1991.

[35] G. Grossman and A. Krueger, "Economic Growth and the Environment," National Bureau of Economic Research w4634, 1994.

[36] R. S. Franklin and M. Ruth, "Growing up and cleaning up: the environmental Kuznets curve redux," Applied Geography, vol. 32, no. 1, pp. 29-39, 2012.

[37] J. Roca, E. Padilla, M. Farré, and V. Galletto, "Economic growth and atmospheric pollution in spain: Discussing the environmental Kuznets curve hypothesis," Ecological Economics, vol. 39, no. 1, pp. 85-99, 2001.

[38] S. Dinda, "Environmental kuznets curve hypothesis: a survey," Ecological Economics, vol. 49, no. 4, pp. 431-455, 2004.

[39] A. Tamazian and B. R. Rao, "Do economic, financial and institutional developments matter for environmental degradation? Evidence from transitional economies," Energy Economics, vol. 32, no. 1, pp. 137-145, 2010.

[40] R. R. Chowdhury and E. F. Moran, "Turning the curve: a critical review of Kuznets approaches," Applied Geography, vol. 32, no. 1, pp. 3-11, 2012.

[41] L. Jianmin, X. Chen, and W. Jinguang, "Fiscal decentralization, governmental competition and environmental pollution: heterogeneity and dynamic effects analysis based on panel data of 272 cities," in Public Finance Research, vol. 9, pp. 36-43, 2015.

[42] X. Helian and D. Yuping, "Does Foreign Direct Investment Lead to Environmental Pollution in China?" Management World, vol. 2, pp. 36-49, 2012 (Chinese).

[43] Y. Wanping, "Dynamic of comprehensive evaluation of china's provincial pollution and research on influencing factors," Economic Management, vol. 32, no. 8, pp. 159-165, 2010 (Chinese).

[44] P. A. P. Moran, “The interpretation of statistical maps," Journal of the Royal Statistical Society A, vol. 10, pp. 243-251, 1948.

[45] S. Chakravorty, J. Koo, and S. V. Lall, "Metropolitan industrial clusters: patterns and processes," in World Bank Policy Research Working Paper, vol. 3073, pp. 1-35, 1-35, 2003.
[46] C. Li and Z. Zhang, "Spatial statistics analysis of regional environmental pollution in China," Energy Procedia, vol. 5, pp. 163-168, 2011.

[47] G. Chi and J. Zhu, "Spatial regression models for demographic analysis," Population Research and Policy Review, vol. 27, no. 1, pp. 17-42, 2008.

[48] J. LeSage and R. K. Pace, Introduction to Spatial Econometrics, Chapman \& Hall/CRC Press, 2009.

[49] L. Anselin, "The Moran scatterplot as an ESDA tool to assess local instability in spatial association," Spatial Analytical Perspectives on GIS, vol. 111, pp. 111-115, 1996.

[50] L. Anselin, Spatial Econometrics: Methods and Models, vol. 4, Springer, 1988.

[51] J. P. Elhorst, "Spatial panel data models," in Handbook of Applied Spatial Analysis, M. M. Fischer and A. Getis, Eds., pp. 377-407, Springer, Berlin, Germany, 2010.

[52] J. P. Elhorst, "Spatial panel data models," in Spatial Econometrics, pp. 37-93, Springer Berlin Heidelberg, 2014.

[53] B. Baltagi, Econometric Analysis of Panel Data, John Wiley \& Sons, 2008.

[54] J. P. Elhorst, "Matlab software for spatial panels," in Proceedings of the IVth World Conference of the Spatial Econometrics Association (SEA), June 2010.

[55] Z. Shuxiao and D. Yong-an, "Heterogeneity, fiscal decentralization and Urban economic growth: research based on panel quantile regression," Journal of Financial Research, vol. 1, pp. 103-105, 2012 (Chinese).

[56] M. Limei and Z. Xiao, “The spatial effect of China's haze pollution and the impact from economic change and energy structure," in China industrial economics, vol. 4, pp. 19-31, 2014.

[57] L.-F. Lee and J. Yu, "Some recent developments in spatial panel data models," Regional Science and Urban Economics, vol. 40, no. 5, pp. 255-271, 2010.

[58] L. Jinyong, J. Yang, and S. Haiyan, "FDI, human capital and environmental pollution in china: a quantile regression analysis based on panel data of 249 cities," Journal of International Trade, vol. 4, pp. 118-125, 2014 (Chinese). 


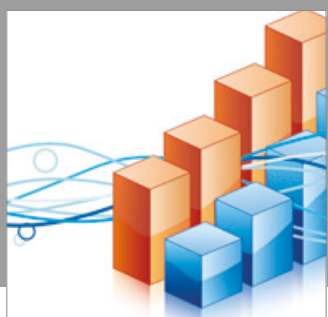

Advances in

Operations Research

vatersals

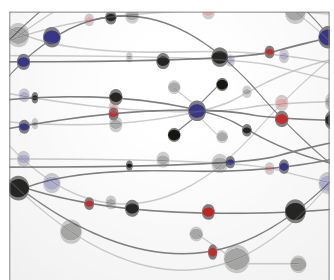

\section{The Scientific} World Journal
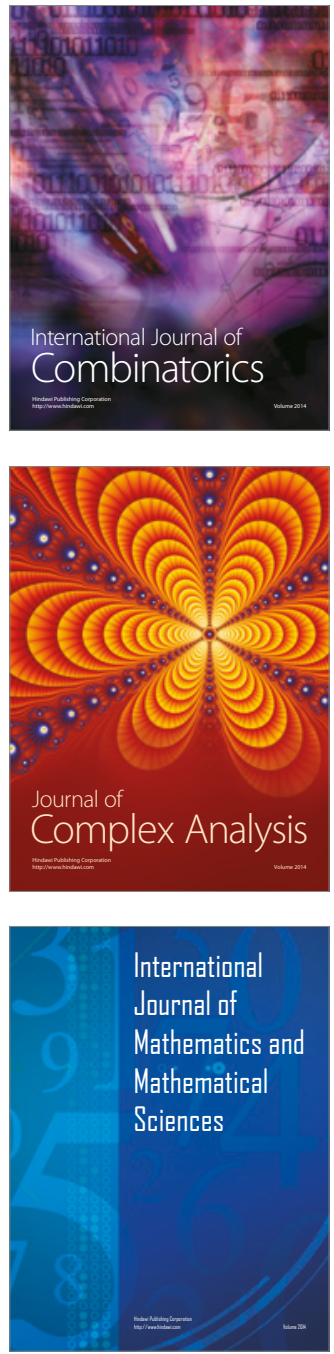
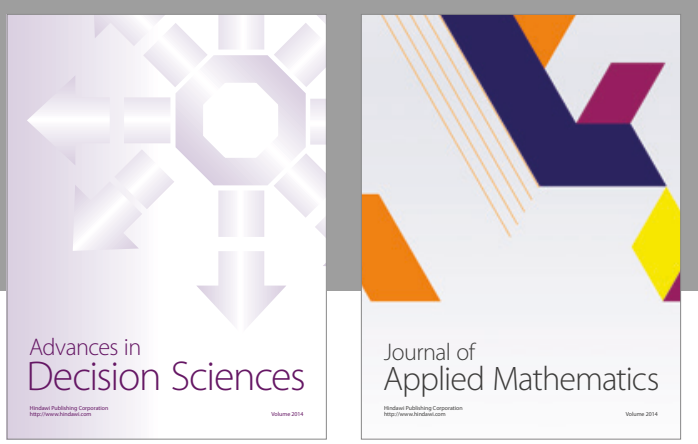

Algebra

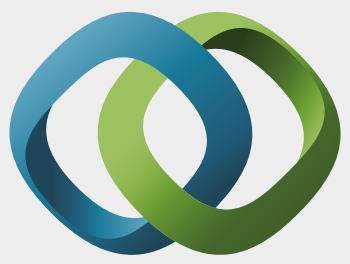

\section{Hindawi}

Submit your manuscripts at

https://www.hindawi.com
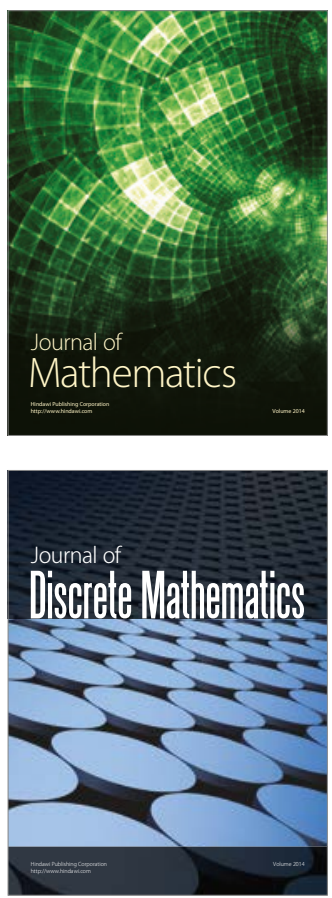

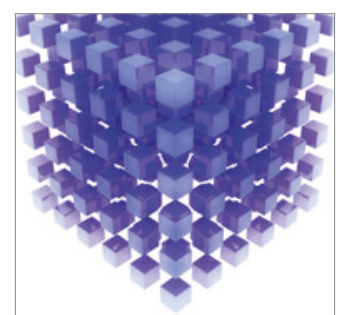

Mathematical Problems in Engineering
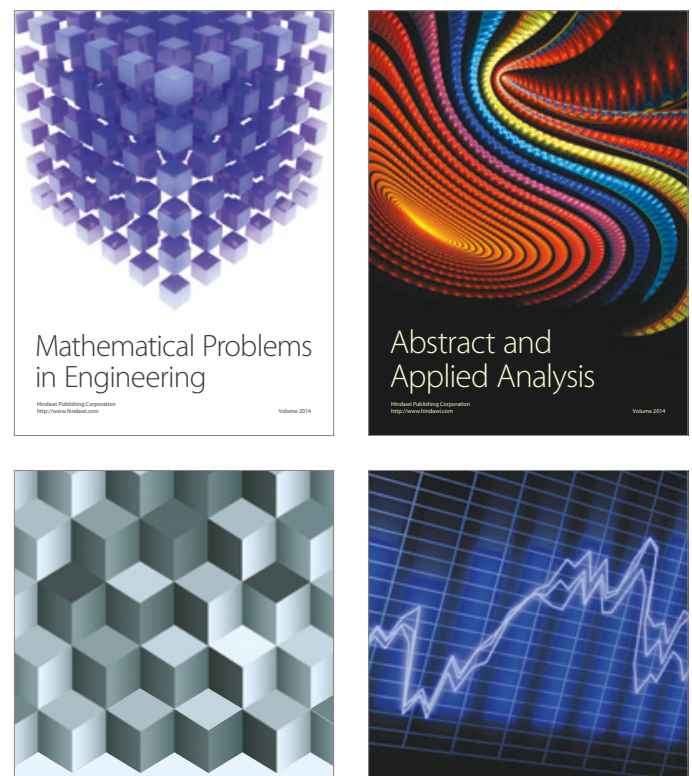

Journal of

Function Spaces

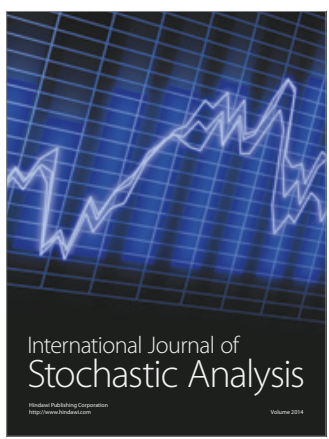

Probability and Statistics
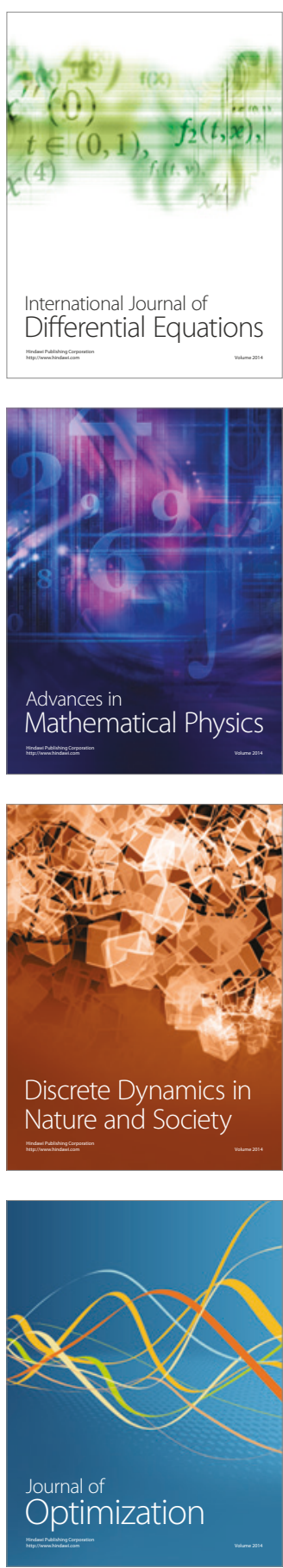